\title{
A survey of current surgical treatment of early stage breast cancer in China
}

\author{
Xin Zhang ${ }^{1}$ and Ying Wang ${ }^{1}$ \\ ${ }^{1}$ Department of Radiation Oncology, Chongqing University Cancer Hospital, Chongqing Cancer Institute, Chongqing Cancer \\ Hospital, Chongqing, People's Republic of China \\ Correspondence to: Ying Wang, email: linmn9@gmail.com \\ Keywords: beast cancer; China; current treatment; questionnaire survey \\ Received: October 10, $2017 \quad$ Accepted: March 22, $2018 \quad$ Published: August 22, 2018 \\ Copyright: Zhang et al. This is an open-access article distributed under the terms of the Creative Commons Attribution License \\ 3.0 (CC BY 3.0), which permits unrestricted use, distribution, and reproduction in any medium, provided the original author and \\ source are credited.
}

\section{ABSTRACT}

The purpose of this national survey is to explore the patterns of surgical management for early stage breast cancer patients in China. A paper questionnaire survey was sent to the representatives from 520 hospitals who attended an international symposium in Guangzhou, China, 2014. The questionnaire included demographic information, initials and most preferred approaches for breast cancer surgery. The results were presented descriptively. The response rate was $42.5 \%$. Only $\mathbf{7} \%$ of hospitals with $>\mathbf{5 0} \%$ rate of breast conserving surgery (BCS). Intraoperative frozen sections and additional cavity margins assessment were used at $88 \%$ and $30.9 \%$ of hospitals, respectively. For invasive carcinoma, $15 \%$ of participants defined an adequate margin as no tumor cells on the ink. Sentinel lymph node biopsy (SLNB) was routinely performed in $93.2 \%$ of hospitals. Only $16.6 \%$ of hospitals would embrace the conclusions of the American College of Surgeons Oncology Group (ACOSOG) Z0011 study and omit axillary lymph node dissection (ALND) for patients who fit the Z0011 criteria. The current patterns for the management of breast cancer patients are still lagging behind. Chinese doctors need to catch up with the updated results of the cutting-edge clinical studies and multiple measures are in need to improve this situation.

\section{INTRODUCTION}

Breast cancer is the most commonly diagnosed cancer and the sixth leading cause of cancer death in Chinese women in 2015 [1]. Increasing numbers of early stage breast cancer patients were detected [2]. A multicenter nationwide study showed that clinical stage I and II breast cancer accounted for $60.6 \%$ of cases in China [3].

Early stage breast cancer management is multidisciplinary in nature, including surgery, radiotherapy and systemic therapy. However, the role of breast surgeons in diagnosis and local oncological control remains significant. It would be informative to know the current surgical treatment status of early stage breast cancer in China. There were several studies that focus on the epidemiology or the current treatment of breast cancer. The patients' information was collected from one province, a nationwide multi-center analysis or an online database [3-5]. However, no detailed information came from a survey of surgeons. The treatment methods received by the Chinese patients are usually dependent on the surgeons' decision making. The surgical practice, attitudes and decision making towards breast cancer surgery may vary among breast surgeons owing to the experiences of the surgeons or the limited resources in some institutions. Therefore, a survey from the surgeons can reflect the current surgical treatment status of early stage breast cancer in China.

The surgical treatment methods for early stage breast cancer are developing quickly, and controversy issues still impact the doctors' decision making and attitudes. There were several surveys sent to members of the medical society regarding controversial issues, such as definition of an adequate margin [6-9]. However, little is known regarding the Chinese breast surgeons' attitudes 
about controversial issues or whether they grasp the new clinical studies.

Therefore, we conducted a national survey by a self-reported written questionnaire that was sent to the participants of a national breast symposium held in Guangzhou city. The purpose of this national survey is to explore the patterns of surgical management for early stage breast cancer patients in China. We will also investigate whether Chinese surgeons can catch up with the results of cutting-edge clinical studies.

\section{RESULTS}

\section{Response rates and demographics}

A total of 221 hospitals responded to the questionnaires, covering all of the mainland, except for Anhui province and the Tibet autonomous region. Of the respondents, a considerable number (36.2\%) were from Guangdong province where the symposium was held. The response rate was $42.5 \%(221 / 520)$, and $86 \%$ of respondents completed the whole questionnaire, while $97 \%$ of respondents completed at least $70 \%$ of the questions.

Most respondents were senior professionals and came from academic-based (76.9\%), "Grade A class 3" $(80.5 \%)$ hospitals. About one half of the department type was breast center. $73.3 \%$ of respondents devoted more than half of their time to breast surgery (Table 1).

\section{Issues of preoperative pathological diagnosis}

We observed that more than $90 \%$ of patients could acquire preoperative pathological diagnosis at only $26.2 \%$ of hospitals. Core needle biopsy was used at most hospitals for breast tumor of BIRADS 1-3 (32.1\%) and BIRADS 4-5(53.8\%). About one fourth of hospitals still chose diagnostic open excisional biopsy for both BIRADS

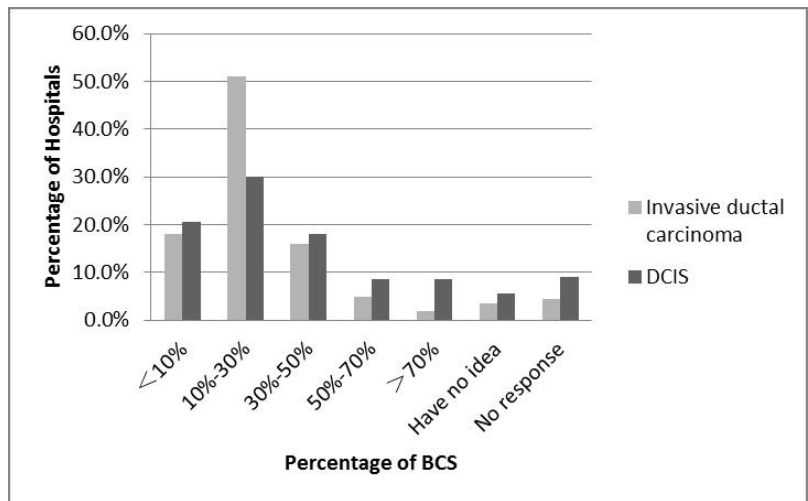

Figure 1: Percentage of BCS for primary invasive ductal carcinoma / DCIS at the surveyed hospitals.
1-3 and BIRADS 4-5 breast tumor (Table 2).

\section{Issues of breast surgery}

In our results, 9.5\% (20/221) of hospitals surveyed never performed BCS. Their reasons were as follows: there was no person skilled at the surgical technique for $\operatorname{BCS}(n=3)$, refusal from patients $(n=8)$, or the lack of radiotherapy department $(n=5)$ or pathology department $(n=2)$. Only $7 \%$ and $17 \%$ of hospitals had more than a $50 \%$ proportion of BCS for primary invasive ductal carcinoma and ductal carcinoma in situ (DCIS), respectively (Figure 1).

In our results, 97\% (195/201) of hospitals used intraoperative techniques to assess the margin status when performing BCS. Additionally, 37.1\% of hospitals assessed cavity margins, $31.4 \%$ used tumor specimen, and $30.9 \%$ used both methods. A majority of (87\%) hospitals chose the intraoperative frozen section to identify the margin status, while a few chose imprint cytology $(2 \%)$, gross inspection $(3 \%)$ and ultrasound $(1 \%)$.

Additionally, participants were asked how to define an adequate margin when performing BCS (Figure 2). For invasive ductal carcinoma, only $15 \%$ considered an adequate margin with no tumor cells on the inked margins, while $42.5 \%$ required $10 \mathrm{~mm}$ of clear tissue, $9.3 \%$ required $1 \mathrm{~mm}, 14.4 \%$ required $2 \mathrm{~mm}$ and $17 \%$ required $5 \mathrm{~mm}$. For DCIS, margins were considered adequate by $21.1 \%$ when there were no tumor cells on the inked margins.

When we asked questions about re-excision with a positive intraoperative margin status, the majority of $(90 \%)$ hospitals considered re-excision of the focal area where the positive margin was located, while $8 \%$ excised the whole cavity again. We also asked whether re-excision of the margins was necessary for atypical hyperplasia. $53.1 \%$ of the hospitals would "sometimes" recommend re-excision for severe atypical hyperplasia and $41.8 \%$ for mild-moderate atypical hyperplasia (figure 3 ). The hospitals surveyed were more likely "always" to recommend re-excision for severe atypical hyperplasia $(37.1 \%)$ than mild -moderate $(11.4 \%)$.

\section{Issues of SLNB}

SLNB was reported to be routinely performed by $93.2 \%$ of the hospitals for patients with clinically negative axillary lymph nodes. The major reasons for abandoning SLNB were lack of resources or equipment $(n=8)$, lack of accurate pathology diagnosis $(n=6)$, or lack of skilled surgical technique $(n=2)$. The majority $(90.5 \%)$ of hospitals could use intraoperative frozen section to analyze the SLNs. When asked about the SLNB technique, $77.7 \%$ of hospitals reported that they use dye only, while 
the remaining $22.3 \%$ used both dye and radiotracer. Of those, methylene blue was the most commonly used dye $(80.5 \%)$.

We asked participants when the immunohistochemical (IHC) stains of the SLNs should be conducted. A small number (4\%) considered that IHC stains of SLNs were necessary when the hematoxylin and eosin (HE) stains were tumor free, while $16.6 \%$ would perform IHC stains regardless of the result of the $\mathrm{HE}$ stains, and $26.1 \%$ recommended it to identify the receptor status of the SLNs when there was a positive result by HE stains. $21.1 \%$ of hospitals never conducted IHC stains.

About one third of hospitals would perform percutaneous node biopsy before SLNB. Of those, 24.1\% used a fine needle aspiration biopsy, while $9.9 \%$ preferred the core needle. When asked, "Does your department conduct ALND for clinical stage T1-2N0M0 breast cancer patients confirmed with 2 or less positive SLNs who received BCS followed by whole breast radiation and adjuvant systemic therapy", a significant proportion $(80 \%)$ of the hospitals answered "Yes". In addition, in a half of hospitals surveyed, SLNB was routinely carried out in breast cancer patients with positive nodes but negative axillary conversion after NACT. $48 \%$ of hospitals carried out SLNB after NACT for clinical axillary negative patients, while $43 \%$ did the opposite.

\section{DISCUSSION}

Our study is the first to report the current surgical treatment status of early stage breast cancer in China based on a questionnaire sent to surgeons during a national symposium. The response rate was $42.5 \%$, which is similar to other surveys in the west $[6,8,9]$. Most respondents came from highly ranked Chinese's hospitals. Two thirds of participants were senior professionals and half worked in specialized breast cancer centers. We inferred that the participant surgeons know very well about the current surgical treatment status of early stage breast cancer in their departments. Therefore, the results of the survey responded by the surgeons could reflect the hospitals.

\section{Issues of preoperative pathological diagnosis}

The European Society of Breast Cancer Specialists (EUSOMA) defined a quality indicator for breast centers, stating that more than $90 \%$ of patients had a preoperative definitive diagnosis [10]. However, in our survey, only $27 \%$ of hospitals reached this standard. A preoperative core needle biopsy is the gold standard method to diagnose primary breast cancer, $[11,12]$ and was endorsed by only half of respondents for BIRADS 4-5 breast tumor in this survey. A study in Beijing also showed that only $34.1 \%$ of the breast cancer patients were diagnosed by a core needle biopsy. However, approximately one fourth of hospitals still chose diagnostic open excisional biopsy frequently for breast tumors, compared with $15 \%-20 \%$ of Canadian and American surgeons in a survey [6]. Excisional biopsy will result in unnecessary surgical procedures and increased cost [13], as well as decreasing the accuracy of the sentinel node biopsy [14].

\section{Issues of breast surgery}

BCS with adjuvant radiotherapy is a standard surgical procedure for early stage breast cancer. In this survey, only a small number of hospitals never developed

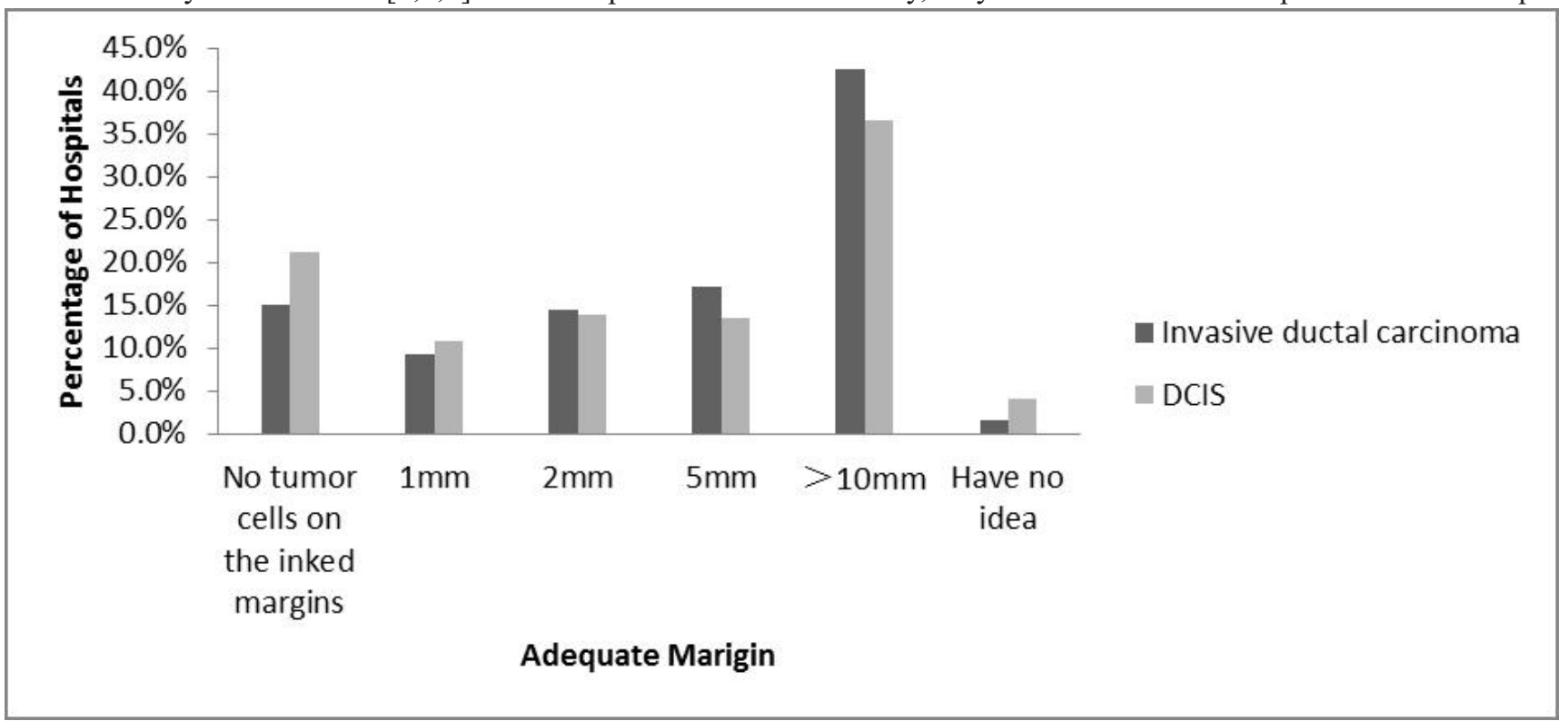

Figure 2: Definition of an adequate margin when performing BCS for invasive ductal carcinoma/DCIS. 
Table 1: Respondent Characteristics

\begin{tabular}{|c|c|c|}
\hline Characteristic & $\mathrm{n}$ & $\%$ \\
\hline \multicolumn{3}{|c|}{ Professional title of the participants } \\
\hline Primary & 18 & 8.1 \\
\hline Intermediate & 52 & 23.5 \\
\hline Senior & 151 & 68.4 \\
\hline \multicolumn{3}{|l|}{ Hospital level } \\
\hline Grade A class 2 & 28 & 12.7 \\
\hline Grade B class 2 & 2 & 0.9 \\
\hline Grade A class 3 & 178 & 80.5 \\
\hline Grade B class 3 & 13 & 5.9 \\
\hline \multicolumn{3}{|l|}{ Practiced facility } \\
\hline Academic & 170 & 76.9 \\
\hline Non-academic & 47 & 21.3 \\
\hline Private & 4 & 1.8 \\
\hline \multicolumn{3}{|l|}{ Department type } \\
\hline Breast cancer center & 128 & 57.9 \\
\hline Non-breast cancer center & 93 & 42.1 \\
\hline \multicolumn{3}{|c|}{ If you devoted more than half time to breast surgery } \\
\hline Yes & 162 & 73.3 \\
\hline No & 59 & 26.7 \\
\hline
\end{tabular}

BCS. However, the rate of BCS was still very low ( $7 \%$ of hospitals with $>50 \%$ rate of BCS), which means that only $7 \%$ reached the higher proportion $(64 \%)$ of BCS in the USA [15]. A nationwide survey in China also reported only $5.5 \%$ of BCS cases [3]. The reasons for the low frequency of BCS in China may be a lack of resources for radiotherapy and pathological supports, or the incomprehension of patients.

Intraoperative margin assessment when performing BCS can reduce final positive margin rates. A frozen section was reported as having the highest sensitivity and specificity compared with imprint cytology or macroscopic assessment $[16,17]$. However, frozen sections increased the operating time from 20-30 min, which may result in additional costs [16]. Margin sampling can come from cavity margins or tumor specimens. Several studies reported that sending a separate cavity margin sample to pathology can help to more easily obtain a negative margin and minimize the local recurrence rates [18-20]. In this survey, almost all hospitals assessed the margin status intraoperatively, and the majority used intraoperative frozen sections. One third of the hospitals assessed both the cavity margins and tumor specimens. In contrast, many surgeons in USA and Canada never use intraoperative frozen sections, nor do they send additional cavities $[6,7]$.

The definition of an adequate margin when performing BCS is a controversial issue. Several major randomized trials did not have a standard definition of the adequate margin. However, "no tumor cells on the inked margin" was considered a sufficient negative margin by the Society of Surgical Oncology (SSO) and the American Society of Radiation Oncology (ASTRO) in a consensus panel in 2013, which was based primarily on a systematic review and meta-analysis $[21,22]$. There existed several surveys about this topic in Western countries. "No tumor cells on the ink" was accepted by $40 \%$ of Canadian respondents [23], 27.6\% of European respondents [9], and $15 \%$ of USA respondents [7]. In our survey, only $15 \%$ of respondents considered an adequate margin with no tumor cells on the inked margins for invasive ductal carcinoma. However, the USA respondents were surveyed in 2009 before the SSO and ASTRO consensus panel. So Chinese surgeons were more likely to support a wider margin.

\section{Issues of SLNB}

SLNB is now considered a standard practice for breast cancer patients with clinically negative axillary lymph nodes. In our survey, $93.2 \%$ of hospitals routinely performed SLNB, compared with $87.8 \%$ in Latino America [24], 52.0\% in United Kingdom [25], 88.9\% in North America and 66.1\% in Europe [26].

A meta-analysis showed that the dual technique (combined with dye and radiotracer) is the gold-standard for the successfully identification of SLNs [27], but dye alone was also reliable and accurate [28]. In our survey, 
Table 2: Preoperative pathological diagnosis

\begin{tabular}{|c|c|c|}
\hline Approach & $\mathrm{n}$ & $\%$ \\
\hline \multicolumn{3}{|l|}{$\begin{array}{l}\text { The percentage of patients who acquired } \\
\text { preoperative pathological diagnosis }\end{array}$} \\
\hline$<30 \%$ & 40 & 18.1 \\
\hline $30 \%-50 \%$ & 39 & 17.6 \\
\hline $50 \%-70 \%$ & 41 & 18.6 \\
\hline $70 \%-90 \%$ & 33 & 14.9 \\
\hline$>90 \%$ & 58 & 26.2 \\
\hline Have no idea & 10 & 4.6 \\
\hline \multicolumn{3}{|l|}{$\begin{array}{l}\text { The method of preoperative pathological } \\
\text { diagnosis for breast tumor of BI-RADS 1-3 }\end{array}$} \\
\hline Fine needle aspiration & 15 & 6.7 \\
\hline Core needle biopsy & 71 & 32.1 \\
\hline Minimally invasion excisional biopsy & 63 & 28.5 \\
\hline Diagnostic open excisional biopsy & 52 & 23.5 \\
\hline No preoperative pathological diagnosis & 17 & 7.7 \\
\hline Have no idea & 3 & 1.5 \\
\hline \multicolumn{3}{|l|}{$\begin{array}{l}\text { The method of preoperative pathological } \\
\text { diagnosis for breast tumor of BI-RADS } 4-5\end{array}$} \\
\hline Fine needle aspiration & 13 & 5.9 \\
\hline Core needle biopsy & 119 & 53.8 \\
\hline Minimally invasion excisional biopsy & 32 & 14.5 \\
\hline Diagnostic open excisional biopsy & 51 & 23.1 \\
\hline No preoperative pathological diagnosis & 4 & 1.8 \\
\hline Have no idea & 2 & 0.9 \\
\hline
\end{tabular}

$22.3 \%$ of hospitals used the dual technique, compared with $64.5 \%$ in the UK [25]. Intraoperative assessment of SLNs allows immediate ALND in patients with positive SLNs, avoiding a second surgery. In our survey, intraoperative frozen section for SLNs analysis was used by the majority (90.5\%) of hospitals, compared with $41.9 \%$ in Latin America and $2.6 \%$ in the UK [24,25].

$\mathrm{IHC}$ techniques were not recommended for routine use by neither NSABP B32 nor ACOSOG Z0010 [29,30]. It is possible that, IHC can be useful for confirming or excluding suspicious findings by HE stains. In our survey, about one fifth used IHC to detect SLNs, and one fourth used it to identify the receptor status of SLNs with positive results by HE stains.

ACOSOG Z0011 showed noninferiority for OS and DFS in breast cancer patients with SLNB alone compared with those undergoing SLNB plus ALND, the included patients were clinical stage T1-2N0M0, which was confirmed with 2 or less positive SLNs and received BCS followed by whole breast radiation and adjuvant systemic therapy [31]. Two studies in the USA reported the impact of the trial on the patterns in the surgeons' practice. One reported that the rate of ALND was smaller after the trial presentation $(84 \%$ to $63 \% ; \mathrm{P}<0.01)$ and publication $(83 \%$ to $62 \% ; \mathrm{P}<0.01$ ) [32]. Similarly, in another report, the rate of ALND decreased from $85 \%$ to $24 \%$ after the release of the trial [33]. However, we observed that $80 \%$ of hospitals still conducted ALND for patients who meet the Z0011 criteria.

Several studies reported that preoperative node sampling by needle biopsy can identify and triage patients with node metastases directly to ALND, avoiding an unnecessary SLNB procedure [34,35]. However in the ACOSOG Z0011 era [31], the value of preoperative node sampling is narrowed to the patients with a larger tumor or who will undergo NACT. In our study, approximately one third of hospitals still performed node biopsy before SLNB.

Even though NACT seems to impact the detection of SLNs and lower the accuracy of SLNB, some studies showed that SLNB can be offered before or after NACT with an acceptable false-negative rate (FNR) [36,37]. In our study, about half of hospitals would conduct SLNB before NACT. Nevertheless, the role of SLNB for patients with clinically positive nodes but negative axillary conversion after NACT remains controversial. The FNR 
for the situation was reported at $14.2 \%$ and $16.7 \%$ by two prospective studies [38,39]. However, there were no positive results in local axillary recurrence reported. Therefore, we have no idea whether the high FNR can result in a worse outcome because of high developed radiotherapy and systemic therapy. We also observed that the hospitals surveyed hold different opinions.

In general, we found that both overtreatment and undertreatment for patients with early stage breast cancer occurred. Preoperative diagnosis was insufficient and some participants still used excisional biopsy. Almost all hospitals can carry out BCS, but the proportion of BCS was considerable lower than the developed countries. Compared with the Western countries, Chinese surgeons have a more conservative attitude. Intraoperative frozen sections and additional cavity margins assessment during BCS were used more frequently in China, and Chinese surgeons were more likely to support a wider margin. When conducting SLND, Chinese surgeons preferred intraoperative frozen sections and IHC techniques. Furthermore, the recent topics seemed to have less impact on the practice of Chinese surgeons, such as ACOSOG Z0011. And Chinese surgeons also did not reach an agreement on the controversial issues, such as the sequence between SLNB and NACT.

Chinese doctors should pay more attention to the most updated guidelines or consensuses about the treatment of breast cancer to improve the outcome of patients in China.

\section{Limitations}

There were several limitations in our study. First, the survey was based on a self-reported questionnaire, which might not reflect actual practice patterns. Second, one third of respondents were from Guangdong province where the symposium was held, and some province had only one responder. So, the differences between locations could not be analyzed and presented. Furthermore, almost all participants came from high level hospitals, and the status of some rural or community hospitals was unclear. Lastly, the questionnaire design could not cover the reasons of the chosen treatment option. And we need further study to explore the reasons.

\section{METHODS}

\section{Survey methodology}

The design of this study was an anonymous survey that was sent to the surgeons who attended the 5th International Oncoplastic Breast Surgery Symposium in Guangzhou, China from September 18 to September 22, 2014. Approximately 1000 participants from 520 hospitals attended the symposium. An initial paper version of the questionnaire was sent to a surgeon who was selected randomly as the representative of one hospital. The results of the survey responded by the surgeons could reflect the hospitals. One day later, an oral reminder was sent to the non-responders. At the end of the symposium, the completed questionnaires were collected.

\section{Questionnaire}

The questionnaire was constructed by the authors, in consultation with professors from Breast Tumor Center at Sun Yat-sen Memorial Hospital.

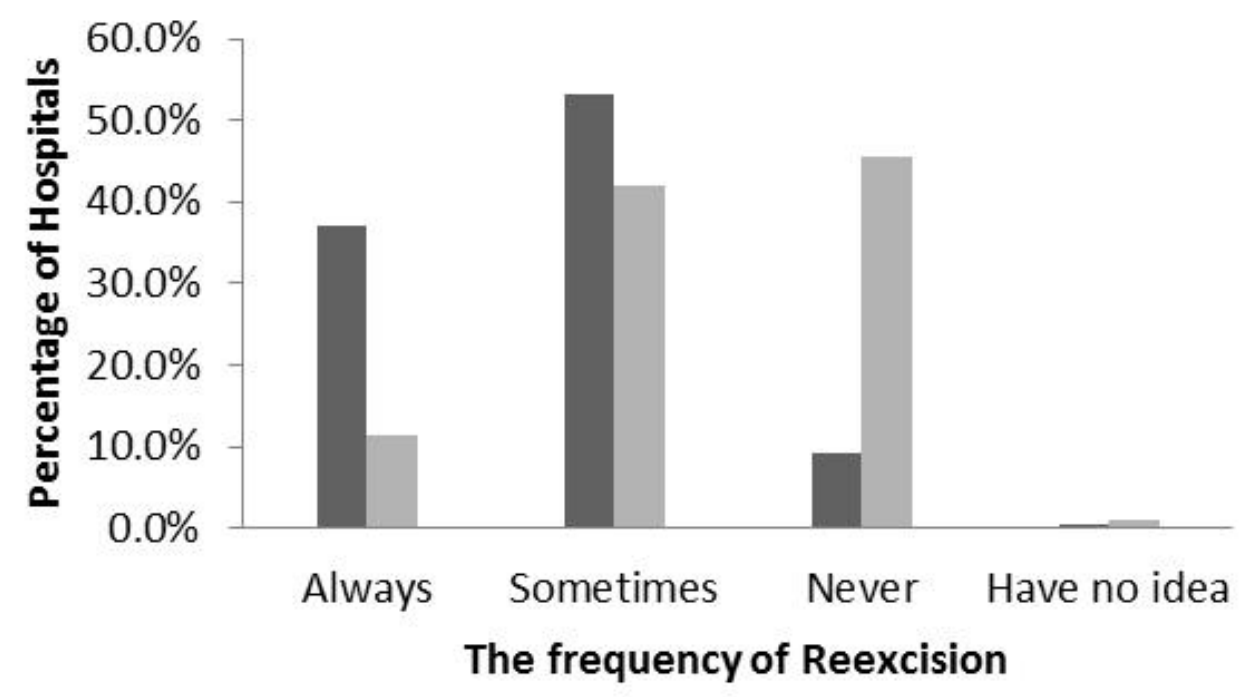

Severe

Mild-moderate

Figure 3: How frequently the hospitals perform of margins with severe/mild-moderate atypical hyperplasia. 
The survey was subsequently pilot tested with 10 surgeons from other hospitals in Guangdong province. They responded to the survey and gave feedback on it. The survey was revised according to their suggestions. Answers from the 10 surgeons for survey development were not included in this data set.

The questionnaire was divided into four sections. The first section was regarding demographic issues such as the hospital's location and categories, as well as the department characteristic. The second section concerned preoperative pathological diagnosis. In the third section, participants were asked about the proportion of BCS, methods for intra-operative margin assessment, definition of adequate margin and extent of resection. The last section was about sentinel lymph node biopsy (SLNB), such as the methods to detect and analyze sentinel lymph nodes (SLNs), the recognition of Z0011 trial result, the sequence between SLNB and neoadjuvant chemotherapy (NACT).

\section{Statistical analysis}

All data were coded and checked for errors by the principal investigator. Missing and ambiguous responses were excluded from the analysis. The results of surveys were entered into a database and analyzed by using SPSS (Version 19.0, IBM Crop, New York, USA). The results were classified by the percentage distribution and presented descriptively

\section{CONCLUSION}

To the best of our knowledge, our study is the first to report the current treatment status of early stage breast cancer based on a questionnaire survey of hospitals. There were issues of both overtreatment and undertreatment for patients with early stage breast cancer. During BCS and SLND, Chinese surgeons kept a more conservative attitude. The current patterns for the management of breast cancer patients are still lagging behind. Chinese doctors need to catch up with the updated results of cutting-edge clinical studies and multiple measures are in need to improve this situation.

\section{Abbreviations}

breast conserving surgery (BCS), Sentinel lymph node biopsy (SLNB), American College of Surgeons Oncology Group (ACOSOG), axillary lymph node dissection (ALND), sentinel lymph nodes (SLNs), neoadjuvant chemotherapy (NACT), ductal carcinoma in situ (DCIS), immunohistochemical (IHC), European Society of Breast Cancer Specialists, (EUSOMA), Society of Surgical Oncology (SSO), the American Society of Radiation Oncology, (ASTRO), false-negative rate (FNR).

\section{Author Contributions}

The manuscript was written through contributions of all authors. All authors have given approval to the final version of the manuscript.

\section{ACKNOWLEDGMENTS}

The authors thank all the study subjects and referring oncologists for their participation in this study.

\section{CONFLICTS OF INTEREST}

The authors declare no potential conflicts of interest.

\section{REFERENCES}

1. Torre LA, Bray F, Siegel RL, Ferlay J, Lortet-Tieulent J, Jemal A. Global cancer statistics, 2012. CA Cancer J Clin. 2015; 65:87-108.

2. Chen W, Zheng R, Baade PD, Zhang S, Zeng H, Bray F, Jemal A, Yu XQ, He J. Cancer statistics in China, 2015. CA Cancer J Clin. 2016; 66:115-32.

3. Li J, Zhang BN, Fan JH, Pang Y, Zhang P, Wang SL, Zheng S, Zhang B, Yang HJ, Xie XM, Tang ZH, Li H, Li JY, et al. A nation-wide multicenter 10-year (1999-2008) retrospective clinical epidemiological study of female breast cancer in China. BMC Cancer. 2011; 11:364.

4. Fan L, Zheng Y, Yu KD, Liu GY, Wu J, Lu JS, Shen KW, Shen ZZ, Shao ZM. Breast cancer in a transitional society over 18 years: trends and present status in Shanghai, China. Breast Cancer Res Treat. 2009; 117:409-16.

5. Yuan XM, Wang N, Ouyang T, et al. Current status of diagnosis and treatment of primary breast cancer in beijing, 2008. Chung-kuo yen cheng yen chiu. 2011;23:38-42.

6. Parvez E, Hodgson N, Cornacchi SD, Ramsaroop A, Gordon M, Farrokhyar F, Porter G, Quan ML, Wright F, Lovrics PJ. Survey of American and Canadian general surgeons' perceptions of margin status and practice patterns for breast conserving surgery. Breast J. 2014; 20:481-88.

7. Blair SL, Thompson K, Rococco J, Malcarne V, Beitsch PD, Ollila DW. Attaining negative margins in breastconservation operations: is there a consensus among breast surgeons? J Am Coll Surg. 2009; 209:608-13. 
8. Azu M, Abrahamse P, Katz SJ, Jagsi R, Morrow M. What is an adequate margin for breast-conserving surgery? Surgeon attitudes and correlates. Ann Surg Oncol. 2010; 17:558-63.

9. Taghian A, Mohiuddin M, Jagsi R, Goldberg S, Ceilley E, Powell S. Current perceptions regarding surgical margin status after breast-conserving therapy: results of a survey. Ann Surg. 2005; 241:629-39.

10. Del Turco MR, Ponti A, Bick U, Biganzoli L, Cserni G, Cutuli B, Decker T, Dietel M, Gentilini O, Kuehn T, Mano MP, Mantellini P, Marotti L, et al. Quality indicators in breast cancer care. Eur J Cancer. 2010; 46:2344-56.

11. Silverstein MJ, Recht A, Lagios MD, Bleiweiss IJ, Blumencranz PW, Gizienski T, Harms SE, Harness J, Jackman RJ, Klimberg VS, Kuske R, Levine GM, Linver $\mathrm{MN}$, et al. Special report: Consensus conference III. Imagedetected breast cancer: state-of-the-art diagnosis and treatment.

12. Kaufman CS, Landercasper J. Can we measure the quality of breast surgical care? Ann Surg Oncol. 2011; 18:3053-60.

13. Blitz A. Where is the outrage? Isr Med Assoc J. 2010; 12:127.

14. Krag DN, Anderson SJ, Julian TB, Brown AM, Harlow SP, Ashikaga T, Weaver DL, Miller BJ, Jalovec LM, Frazier TG, Noyes RD, Robidoux A, Scarth HM, et al, and National Surgical Adjuvant Breast and Bowel Project. Technical outcomes of sentinel-lymph-node resection and conventional axillary-lymph-node dissection in patients with clinically node-negative breast cancer: results from the NSABP B-32 randomised phase III trial. Lancet Oncol. 2007; 8:881-88.

15. McGuire KP, Santillan AA, Kaur P, Meade T, Parbhoo J, Mathias M, Shamehdi C, Davis M, Ramos D, Cox CE. Are mastectomies on the rise? A 13-year trend analysis of the selection of mastectomy versus breast conservation therapy in 5865 patients. Ann Surg Oncol. 2009; 16:2682-90.

16. Jorns JM, Visscher D, Sabel M, Breslin T, Healy P, Daignaut $\mathrm{S}$, Myers JL, Wu AJ. Intraoperative frozen section analysis of margins in breast conserving surgery significantly decreases reoperative rates: one-year experience at an ambulatory surgical center. Am J Clin Pathol. 2012; 138:657-69.

17. Sumiyoshi K, Nohara T, Iwamoto M, Tanaka S, Kimura K, Takahashi Y, Kurisu Y, Tsuji M, Tanigawa N. Usefulness of intraoperative touch smear cytology in breast-conserving surgery. Exp Ther Med. 2010; 1:641-45.

18. Hequet D, Bricou A, Koual M, et al. Systematic cavity shaving: modifications of breast cancer management and long-term local recurrence, a multicentre study. Eur J Surg Oncol. 2013; 39:899-905.

19. Moo TA, Choi L, Culpepper C, Olcese C, Heerdt A, Sclafani L, King TA, Reiner AS, Patil S, Brogi E, Morrow M, Van Zee KJ. Impact of margin assessment method on positive margin rate and total volume excised. Ann Surg
Oncol. 2014; 21:86-92.

20. Barthelmes L, Al Awa A, Crawford DJ. Effect of cavity margin shavings to ensure completeness of excision on local recurrence rates following breast conserving surgery. Eur J Surg Oncol.2003; 29:644-648.

21. Moran MS, Schnitt SJ, Giuliano AE, Harris JR, Khan SA, Horton J, Klimberg S, Chavez-MacGregor M, Freedman G, Houssami N, Johnson PL, Morrow M. Society of Surgical Oncology-American Society for Radiation Oncology consensus guideline on margins for breast-conserving surgery with whole-breast irradiation in stages I and II invasive breast cancer. Ann Surg Oncol. 2014; 21:704-16.

22. Houssami N, Macaskill P, Marinovich ML, Morrow M. The association of surgical margins and local recurrence in women with early-stage invasive breast cancer treated with breast-conserving therapy: a meta-analysis. Ann Surg Oncol. 2014; 21:717-30.

23. Lovrics PJ, Gordon M, Cornacchi SD, Farrokhyar F, Ramsaroop A, Hodgson N, Quan ML, Wright F, Porter G. Practice patterns and perceptions of margin status for breast conserving surgery for breast carcinoma: National Survey of Canadian General Surgeons. Breast. 2012; 21:730-34.

24. Acuna SA, Angarita FA, Escallon J. Assessing patterns of practice of sentinel lymph node biopsy for breast cancer in Latin America. World J Surg. 2014; 38:1077-83.

25. Mansfield L, Sosa I, Dionello R, Subramanian A, Devalia $\mathrm{H}$, Mokbel K. Current management of the axilla in patients with clinically node-negative breast cancer: a nationwide survey of United Kingdom breast surgeons. Int Semin Surg Oncol. 2007; 4: 4.

26. Ceilley E, Jagsi R, Goldberg S, Grignon L, Kachnic L, Powell S, Taghian A. Radiotherapy for invasive breast cancer in North America and Europe: results of a survey. Int J Radiat Oncol Biol Phys. 2005; 61:365-73.

27. Kim T, Giuliano AE, Lyman GH. Lymphatic mapping and sentinel lymph node biopsy in early-stage breast carcinoma: a metaanalysis. Cancer. 2006; 106:4-16.

28. Chintamani TM, Tandon M, Mishra A, Agarwal U, Saxena S. Sentinel lymph node biopsy using dye alone method is reliable and accurate even after neo-adjuvant chemotherapy in locally advanced breast cancer - a prospective study. World J Surg Oncol. 2011; 9:19.

29. Krag DN, Anderson SJ, Julian TB, Brown AM, Harlow SP, Costantino JP, Ashikaga T, Weaver DL, Mamounas EP, Jalovec LM, Frazier TG, Noyes RD, Robidoux A, et al. Sentinel-lymph-node resection compared with conventional axillary-lymph-node dissection in clinically node-negative patients with breast cancer: overall survival findings from the NSABP B-32 randomised phase 3 trial. Lancet Oncol. 2010; 11:927-33.

30. Giuliano AE, Hawes D, Ballman KV, Whitworth PW, Blumencranz PW, Reintgen DS, Morrow M, Leitch AM, Hunt KK, McCall LM, Abati A, Cote R. Association of 
occult metastases in sentinel lymph nodes and bone marrow with survival among women with early-stage invasive breast cancer. JAMA. 2011; 306:385-93.

31. Giuliano AE, Ballman KV, McCall L, Beitsch PD, Brennan MB, Kelemen PR, Ollila DW, Hansen NM, Whitworth PW, Blumencranz PW, Leitch AM, Saha S, Hunt KK, Morrow M. Effect of Axillary Dissection vs No Axillary Dissection on 10-Year Overall Survival Among Women With Invasive Breast Cancer and Sentinel Node Metastasis: The ACOSOG Z0011 (Alliance) Randomized Clinical Trial. JAMA. 2017; 318:918-26

32. Robinson KA, Pockaj BA, Wasif N, Kaufman K, Gray RJ. Have the American College of Surgeons Oncology Group Z0011 trial results influenced the number of lymph nodes removed during sentinel lymph node dissection? Am J Surg. 2014; 208:1060-64.

33. Caudle AS, Hunt KK, Tucker SL, Hoffman K, Gainer SM, Lucci A, Kuerer HM, Meric-Bernstam F, Shah R, Babiera GV, Sahin AA, Mittendorf EA. American College of Surgeons Oncology Group (ACOSOG) Z0011: impact on surgeon practice patterns. Ann Surg Oncol. 2012; 19:314451.

34. Houssami N, Ciatto S, Turner RM, Cody HS 3rd, Macaskill P. Preoperative ultrasound-guided needle biopsy of axillary nodes in invasive breast cancer: meta-analysis of its accuracy and utility in staging the axilla. Ann Surg. 2011; 254:243-51.

35. Rautiainen S, Masarwah A, Sudah M, Sutela A, Pelkonen O, Joukainen S, Sironen R, Kärjä V, Vanninen R. Axillary lymph node biopsy in newly diagnosed invasive breast cancer: comparative accuracy of fine-needle aspiration biopsy versus core-needle biopsy. Radiology. 2013; 269:54-60.

36. Buchholz TA, Lehman CD, Harris JR, Pockaj BA, Khouri N, Hylton NF, Miller MJ, Whelan T, Pierce LJ, Esserman LJ, Newman LA, Smith BL, Bear HD, Mamounas EP. Statement of the science concerning locoregional treatments after preoperative chemotherapy for breast cancer: a National Cancer Institute conference. J Clin Oncol. 2008; 26:791-97.

37. Gui G. Meta-analysis of sentinel lymph node biopsy after preoperative chemotherapy in patients with breast cancer (Br J Surg 2006: 93: 539-546). Br J Surg. 2006; 93:102526.

38. Kuehn T, Bauerfeind I, Fehm T, Fleige B, Hausschild M, Helms G, Lebeau A, Liedtke C, von Minckwitz G, Nekljudova V, Schmatloch S, Schrenk P, Staebler A, Untch M. Sentinel-lymph-node biopsy in patients with breast cancer before and after neoadjuvant chemotherapy (SENTINA): a prospective, multicentre cohort study. Lancet Oncol. 2013; 14:609-18.

39. Lee HD, Ahn SG, Lee SA, Lee HM, Jeong J. Prospective evaluation of the feasibility of sentinel lymph node biopsy in breast cancer patients with negative axillary conversion after neoadjuvant chemotherapy. Cancer Res Treat. 2015; 47:26-33. 